NASA Technical Memorandum 106387

AIAA-93-4865

\title{
Overview of STOVL Aircraft Propulsion Research Offtakes andVertical Lift Systems
}

Thomas J. Biesiadny, Jack G. McArdle, and Barbara S. Esker

Lewis Research Center

Cleveland, Ohio

Prepared for the

International Powered Lift Conference

sponsored by the American Institute of Aeronautics and Astronautics

Santa Clara, California, December 1-3, 1993 


\author{
Thomas J. Biesiadny, Jack G. McArdle, and Barbara S. Esker \\ National Aeronautics and Space Administration \\ Lewis Research Center \\ Cleveland, Ohio 44135
}

\begin{abstract}
$\underline{\text { Abstract }}$
The overall Short Takeoff and Vertical Landing (STOVL) Aircraft Propulsion Research Program includes key technologies involving offtake systems, vertical lift systems, hot gas ingestion, STOVL augmentors, and integrated flight propulsion controls. A part of the NASA Lewis work involving STOVL aircraft propulsion systems is presented with the emphasis on component-level experiments and analysis related to offtakes and vertical lift systems.
\end{abstract}

\section{Introduction}

After the turn of the century, the military is likely to need replacement fighter/attack aircraft. Supersonic short takeoff and vertical landing (STOVL) capabilities would offer enhanced mission capability, operational flexibility, survivability, and utility over conventional replacement aircraft. Significant work has been done to identify and resolve critical technology issues related to this type of aircraft. Key propulsion-related technologies include offtake systems, exhaust systems, hot gas ingestion, augmentors, and integrated controls. The work at Lewis on STOVL propulsion systems has primarily focused on component-level experimental and analytical research. This research has provided data bases for the verification of design technology and for the calibration of the CFD tools available for design use. Presented herein is a summary of the work related to offtakes and exhaust (i.e., vertical lift) systems.

\section{Background}

Propulsion system technology levels have advanced to the stage that a supersonic STOVL aircraft appears feasible. Even so, there are several areas that require consideration before a supersonic STOVL aircraft and propulsion system can be considered for operational status. These critical technologies include, but are not limited to, highperformance and low-loss exhaust gas offtakes and ducts that deliver flow to the vertical thrusting systems and vertical lift nozzles. Progress has been made in these basic research areas, but there is much to be done and resources are limited. The propulsion system remains the key factor in any STOVL concept.

\section{$\underline{\text { Objective }}$}

The objective of the NASA Lewis STOVL aircraft propulsion program has been to provide data bases for the verification of design technology and for the calibration of CFD tools for design use.

\section{Approach}

As part of the supersonic STOVL effort, the United States and the United Kingdom entered into a joint program in the mid-1980's. Studies conducted by engine and airframe manufacturers in both countries identified critical technology needs for future supersonic STOVL aircraft. NASA Lewis has been involved with the following elements: exhaust gas offtakes and ducts, vertical lift nozzles, integrated flight-propulsion controls, hot gas ingestion, and STOVL augmentors. The approach has been to conduct component-level experimental and analytical research in each of these. This paper describes our work in the specific areas of exhaust gas offtakes and ducts and vertical lift systems.

\section{Offtakes and Ducts}

In many of the STOVL-aircraft concepts studied, air from the engine must be brought forward through offtake ducts and valves to vertical lift devices forward of the engine. A generic one-third-scale model of a tailpipe offtake system (Fig. 1) was tested at Lewis. ${ }^{1}$ The model consisted of a tailpipe with elbows, ducts, and flow control nozzles, a blind flange to simulate a blocked cruise nozzle, and a small ventral nozzle. The test hardware was designed to be modular. Additional research with variations of the generic, or baseline, configuration was done. Typical results include flow visualization photographs and aerodynamic performance data.

\section{Generic Offtake System}

The generic one-third-scale model of a tailpipe offtake system (without a centerbody) (Fig. 1) had a flow split of 45 percent to each offtake and 10 percent to the ventral nozzle. The offtake flow turned through a total of $177^{\circ}$ relative to the tailpipe inlet axis. Performance tests were 
made with unheated air at tailpipe-to-ambient pressure ratios from approximately 2 to 5 at a tailpipe Mach number of 0.3 . Generalized results having applications to flight hardware design are summarized as follows:

(1) The turning pressure loss in the offtake ducting was 15.5 percent of the tailpipe total pressure at a tailpipe Mach number of 0.307 when the offtake flow control nozzles were choked. This is equivalent to a loss of 2.5 times the tailpipe dynamic pressure. This result is significant because pressure loss translates into thrust loss for the vertical lift system. Nearly all the pressure loss occurred in turning the flow from the tailpipe into and through the elbows. Turning aids at the offtake openings, such as rounded edges or guide vanes, are needed to reduce offtake pressure loss. Turning vanes may have to be tailored to the variations in flow approach angles at the tailpipe openings.

(2) Flow patterns at the offtake opening were complex. Much of the flow entered the aft part of the opening and followed the outside wall of the elbow downstream. Other flow swirled into the bottom part of the opening and filled in the lower pressure region near the inside wall. The flow was reasonably uniform at the ends of the long offtake ducts. Therefore, ducts should be long to promote flow uniformity.

(3) Wall pressures throughout the tailpipe were less than 96 percent of the tailpipe total pressure and in the offtake ducting were less than 88 percent. Wall pressures are low enough that turbofan engine bypass air probably can be used for wall cooling.

(4) Ventral flow was concentrated in the aft part of the duct and was not uniform at the ventral nozzle inlet because the duct was short. A small amount of ventral flow may not affect the pressure loss in an offtake system.

(5) When the ventral nozzle was closed off, the offtake flow and pressure loss remained the same, but the offtake inflow pattern, such as the approach and swirl angles, changed. The data obtained in these tests did not reveal the details of this behavior.

(6) No significant periodic pressure fluctuations were measured at the offtake openings or at the blocked end of the tailpipe.

\section{Offtake System Variations}

Considering the large pressure losses discovered in the generic system, an attempt was made to better understand the loss mechanisms and to lessen the pressure loss. Modifications were made to the basic configuration shown in Fig. 1 to measure the effects of flow-path changes on the flow and pressure-loss characteristics. ${ }^{2}$ The modified configurations (Fig. 2) included
(1) Adding a centerbody (Fig. 2(a)) to change the position of the offtake openings with regard to the simulated turbine discharge location (The absence of a centerbody (Fig. 1) simulated a turbine discharge location far upstream of the offtake openings.)

(2) Changing the location of the openings along the tailpipe with respect to the centerbody (not shown in Fig. 2)

(3) Rounding the offtake entrances (Fig. 2(b)) by adding inserts at the forward edges

(4) Blocking the tailpipe just aft of the openings (Figs. 2(c) and (d)), but upstream of the ventral nozzle position, instead of at the cruise nozzle position

The general objective of this testing was to investigate trends in offtake pressure loss and total-pressure distribution for configuration features expected to affect performance. The tailpipe Mach number was varied from 0.2 to 0.4 . The tests were performed at tailpipe-to-ambient pressure ratios from 1.4 to 5 .

For all the configurations tested, the offtake pressure loss and other flow parameters were constant at pressure ratios greater than needed to choke the offtake flow control nozzles.

For the model with the centerbody (Fig. 2(a)) after choked flow, the offtake pressure loss up to the entrance of the downward-pointing elbows increased nonlinearly with the annulus Mach number (or, alternatively, total airflow referred to annulus conditions). An additional loss, about $0.25 \mathrm{q}$, occurred in the downward-pointing elbow, where $q$ is the dynamic pressure at the elbow entrance (a $0.25 q$ loss is about what is expected for a typical elbow with uniform inflow). The total offtake system loss varied from 11 percent at an annulus Mach number of 0.29 to 27 percent of the annulus total pressure at a Mach number of 0.48 . It should be remembered that this was a basic system with no attempt to assist turning. Therefore, the system may represent a configuration in which the maximum losses occur. Other key findings include the following:

(1) When the offtake openings were located closer to the centerbody tailcone (position not shown in Fig. 2(a)), the pressure loss and flow capacity were not changed significantly. The centerbody was then removed to increase the tailpipe flow area ahead of the offtake openings as though the openings were far downstream of the simulated turbine exit. Compared to the basic configuration (Fig. 2(a)), the offtake pressure loss was reduced about 3 percentage points for the same flow rate. 
(2) The pressure loss and flow capacity were not changed significantly when rounded entrances (Fig. 2(b)) were added to the upstream edge of the tailpipe offtake openings. It was felt that this was caused by the large flow separation at the upstream edge of the offtake opening.

(3) At an annulus Mach number of about 0.42 , the offtake pressure loss was reduced by 6 percentage points when a shaped tailpipe blocker (Fig. 2(d)) was mounted just aft of the offtake openings. The blocker also raised the flow capacity of the system almost 9 percent, apparently by guiding the flow into the openings. This increased flow capacity meant a lower total-pressure loss as the flow moved through the openings and a higher total pressure at the offtake nozzle. The higher total pressure assured a higher flow rate. A flat blocker (Fig. 2 (c)) also reduced the pressure loss and raised the flow capacity, but to a lesser extent.

Flow visualization paint streaks at an offtake opening in the tailpipe of the basic configuration revealed flow upwash leading to spiral nodes on the centerbody tailcone (Fig. 3). The paths of the vortical flow leaving the spiral nodes were not determined. Other paint streaks and a flowangle probe traverse at the opening showed a large-scale swirl in the flow entering the offtake (Fig. 4) in a manner similar to flow patterns in a model without a centerbody. The total-pressure gradient in the offtake flow was large at the offtake elbow but typically was reduced to only about 5 percent distortion at the ends of the long offtake ducts. The large-scale swirl persisted in the flow through the ducts.

Flow visualization paint streaks in one of the downturn elbows showed that a secondary flow pattern expected from classical fluid dynamics was superimposed on the bulk flow, although the secondary pattern was distorted slightly because of the flow swirl entering the elbow.

\section{Vertical Lift Systems}

NASA Lewis has also investigated design criteria and developed a technology base for vertical lift thrust nozzles. One major objective was to establish aerodynamic design principles and a data base for vertical lift components through experimental testing and CFD analyses.

\section{Generic Ventral Nozzle System}

Flow in a generic ventral nozzle system (Fig. 5), the baseline for subsequent research, was studied experimentally and analytically ${ }^{3}$ with a block version of the PARC3D CFD program (a full Navier-Stokes equation solver) to evaluate the program's ability to predict system performance and internal flow patterns. For the experimental work, a one-third-scale model tailpipe with a single, large, rectangular ventral nozzle mounted normal to the tailpipe centerline was tested with unheated air at steady-state pressure ratios from 1.6 to 4.0. The end of the tailpipe was closed to simulate a blocked cruise, or exhaust, nozzle.

Measurements showed about a 5.5-percent totalpressure loss due to flow turning, reasonable nozzle performance coefficients, and a significant aftward axial component of thrust due to a flow turning of more than $90^{\circ}$. The flow behavior into and through the ventral duct was illustrated with paint streak flow visualization photographs. A typical result (not shown in Fig. 5) was that a low-density region of separated vortical flow occurred at the upstream wall of the ventral duct. Flow was strong in the downstream part of the duct and tended to move toward the upstream wall. This pattern persisted through the nozzle exit and caused an axial component (i.e., a negative longitudinal thrust component) measured by the thrust system.

For the analytical work, the same ventral system configuration was modeled with two computational grids to evaluate the effect of grid density. Both grids gave good results. The finer grid solution produced more detailed flow patterns and predicted performance parameters, such as thrust and discharge coefficient, within 1 percent of the measured values. PARC3D flow visualization images are shown for comparison with the paint streak photographs (Fig. 5). As a result of this work, this CFD analytical tool, PARC3D, should be considered for use in the analysis of STOVL propulsion ventral nozzle designs.

\section{Annular Flow Path and Shorter Ventral Duct}

The goals of a ventral nozzle system should be to (1) minimize internal pressure losses, (2) maximize vertical thrust produced, and (3) possibly minimize the axial component of the net ventral thrust (i.e., minimize the need to control this force in an actual aircraft installation). With these goals in mind, three design factors for ventral nozzles were investigated ${ }^{4}$ and involved the following configurations (Fig. 6):

(1) An annular tailpipe flow path (Fig. 6(b)) (which simulated the bypass flow of a turboan engine being drawn into the ventral duct and has been referred to as a separate flow system)

(2) A tailpipe flow path, but no centerbody, with a tailpipe blocker immediately downstream of the ventral duct (Fig. 6(c))

(3) A ventral duct length shorter than the baseline length (Fig. 6(d))

Data gathered during these tests included pressure losses, thrust and flow performance, internal flow visualization, and pressure distributions at the exit plane of the ventral nozzle. An analytical study using the PARC3D CFD 
code was also performed on the short ventral duct configuration.

The performance of this system as compared with the baseline configuration (Fig. 6(a)) showed that

(1) The configuration with the tailpipe blocked immediately downstream of the ventral duct had more internal total-pressure loss and a slightly lower system discharge coefficient. This configuration produced slightly less vertical thrust than the baseline and less axial thrust. The elimination of the recirculation region downstream of the ventral opening (shown in Fig. 5) had a slight adverse effect on the performance of the ventral system.

(2) The short ventral duct exhibited the best performance of the three configurations. In comparison with the baseline, this configuration had less internal pressure loss and a slightly higher discharge coefficient. Also, this configuration produced the same vertical thrust and a smaller axial thrust component. These results tend to indicate that the ventral duct can be shortened without adversely affecting the flow and thrust performance.

(3) The annular flow duct configuration had a significantly lower discharge coefficient than that of the baseline configuration. The thrust produced by this configuration had less vertical component and more horizontal component than the thrust produced by the baseline configuration. These results indicate that the attempt to draw flow from an annulus and direct it into the ventral duct resulted in a configuration with poorer performance than one in which the full-duct cross section of the tailpipe flow is redirected.

\section{Ventral and Axial Nozzles}

To examine the flow fields during the transition from hover to wing-borne flight, a configuration with both the ventral and axial nozzles flowing (Fig. 7) was investigated. ${ }^{5}$ The experiment consisted of performance testing over a range of tailpipe pressure ratios from 1.4 to 3.2 and conducting flow visualization studies. Although the tailpipe Mach number was higher, approximately 0.6 , than that in conventional military engines, the configuration exhibited the essential flow features and provided an opportunity to compare analytical and experimental results. The analytical investigation consisted of modeling the same configuration and solving for the flow using the PARC3D CFD code. The comparison of experimental and analytical results for the ventral nozzle data was very good. For example, the ventral nozzle discharge and thrust coefficients obtained from both the experimental and analytical studies agreed within 1.2 percent. On the other hand, the axial nozzle discharge and thrust coefficient variations were as high as 6 percent. It appears that these variations in the flow and thrust coefficients result from a slight increase in total pressure in the downstream section of the tailpipe for the analytical model. This increase in total pressure is created by the artificial dissipation model near the pole boundary condition.

The experimental and analytical studies showed very good agreement in the internal flow patterns. A typical result of the analytical studies (Fig. 8) indicated that the boundary layer was nearly completely drawn off by the ventral nozzle. The boundary layer started to re-form on the ventral duct side of the tailpipe downstream of the ventral duct. On the opposite side of the tailpipe and downstream of the ventral duct, the flow diffused resulting in a distorted condition at the entrance to the axial nozzle. Similar to the results for the generic ventral nozzle (Fig. 5), studies also indicated that the flow separated from the front wall of the ventral duct, and large vortices were formed in this region. As with the generic ventral nozzle, this behavior resulted in a low-pressure region which caused the ventral nozzle air flow to overturn back toward the inlet to the tailpipe and created a significant rearward thrust component. This reverse thrust component adversely affected the horizontal thrust of the axial nozzle and resulted in a low net horizontal thrust coefficient for the nozzle system.

\section{$\underline{\text { Vane Nozzle }}$}

Many conceptual designs for advanced STOVL aircraft need ventral nozzles that can vector the jet to provide forces and moments to control the aircraft's movement or attitude when in ground effect. A type of ventral nozzle that can both vector the jet and vary the jet flow area (Fig. 9) is called a vane nozzle. ${ }^{6}$ The nozzle consists of parallel, spaced-apart flow passages formed by pairs of vanes which can be rotated on axes perpendicular to the flow. The model had three parallel flow passages. Each passage was formed by a vaneset consisting of a long and a short vane. The longer vanes controlled the jet vector angle, and the shorter controlled the flow area. Two important features of this nozzle type are its ability to vector the jet rearward up to $45^{\circ}$ and to produce less harsh pressure and velocity footprints during vertical landing than does an equivalent single jet. The tests were made with the nozzle mounted on the model tailpipe with a blind flange on the end to simulate a closed cruise nozzle. These were performed with unheated air over a range of tailpipe-to-ambient pressure ratios from 1.8 to 4.0 .

The jet vector angle varied smoothly as the long vane angle was changed. At a pressure ratio of 3.0, the resultant force moved from $-16^{\circ}$ (forward direction) to $29^{\circ}$ (rearward direction) when the long vanes were moved from $-19^{\circ}$ to $30^{\circ}$. It is believed that the jet continued to vector smoothly for the deflection of the longer vane to $45^{\circ}$, but reliable force data were not available to verify this.

The nozzle thrust performance was low (measured force coefficients were 0.90 or less over most of the tested ranges) compared with that of other convergent nozzles. A 
conical nozzle force coefficient would be 0.96 or more in the pressure ratio range tested. Thrust losses were mainly caused by internal jet overexpansion and interactions and/or by subambient pressures on exposed surfaces. The computation of this force coefficient was based on the simulated turbine discharge total pressure. Had the nozzle inlet total pressure been used, the coefficient would have been higher.

The airflow rate was controlled by the position of the short vane relative to the long vane, which caused a throat to form in the opening between the vanes (Fig. 9). The performance trends were generally similar for throat areas from 0.79 to 1.21 times the design throat area. The nozzle flow capacity was acceptable. The measured discharge coefficients were greater than 0.92 over most of the ranges tested. A conical nozzle would have about the same discharge coefficient in this pressure ratio range.

Subambient pressures were developed in the cavities between vanesets (Fig. 9). Air from a separate source in amounts up to 1.5 percent of the tailpipe flow was injected equally into the cavities and caused no significant changes in nozzle performance. Up to 4.5 percent of the tailpipe flow was injected into only one of the cavities without increasing the pressure in any of the cavities, which implied that the nozzle could be made to pump large quantities of air, like an ejector.

The peak footprint velocity and pressure (Fig. 10) were less than those caused by another single-jet nozzle that could be suitable for similar applications (such as the swivel nozzle to be described next). These results are attributed to the long, narrow, spaced-apart jets from the vane nozzle which dissipate energy more rapidly than a single jet.

Tests of single vanesets having equal-length and longshort vanes showed significant differences in flow-turning performance (Fig. 11). The long-short design turned the jet through a larger vector angle than the equal-length design did for the same angular travel of the vanes, and the discharge and force coefficients were as good as or better than those achieved with equal-length vanes.

The vane nozzle has features that make it attractive for flight application: wide ranges of throat area and jet vectoring and less harsh total pressure and velocity footprints than those of other useful vectoring nozzles. At the same time, the vane nozzle has a comparatively complex configuration, high hinge moments on vanes that turned the flow (also, moments were in directions that tended to open the throat), long seal runs, and low thrust performance.

\section{$\underline{\text { Swivel Nozzle }}$}

Another possible method to provide thrust vectoring with a ventral nozzle but with perhaps less complexity than with the vane nozzle is to implement a clam-shell, twodimensional converging nozzle. ${ }^{7}$ This nozzle (Fig. 12) is capable of vectoring the flow up to $\pm 23^{\circ}$ from the vertical (mid) position. Although in a production design each of the outer shells could be independently actuated, for simplicity in this experiment the exit area and the two outer shells were connected. Two configurations were tested: the swivel nozzle with a square contour of the leading edge of the ventral duct inlet and the same nozzle with a round leadingedge contour.

The presence of a negative horizontal thrust at a vector angle setting of $0^{\circ}$ is important to note. This result is similar to that seen for the generic ventral nozzle. For the square leading-edge configuration, this thrust component was a result of the flow exiting the nozzle at an angle approximately $5^{\circ}$ greater than the nozzle vector angle or geometric setting. The $5^{\circ}$ difference between the effective flow angle and the vector angle setting is the result of a low-pressure region of separated flow along the upstream ventral duct wall. These results are similar to those obtained for the generic ventral nozzle shown in Fig. 5. The round leading edge of the ventral duct reduced the low-pressure region which, in turn, reduced the angle difference. This offset should be accounted for in flight systems design.

Of significance are the data showing the sensitivity of this configuration to severe internal flow angles that could be associated with STOVL applications. Here, rounding the leading edge to the ventral nozzle duct resulted in a significant improvement in nozzle performance. For the square leading edge, the discharge coefficient was dependent on the vector angle setting. At a pressure ratio of 3.0 , it ranged from 0.854 for a $-20^{\circ}$ vector angle to 0.874 for $\mathrm{a}+20^{\circ}$ vector angle. The thrust coefficient was independent of the vector angle setting. It reached a value of 0.97 at a pressure ratio of 3.0. The round leading edge reduced the turning losses and increased the discharge coefficient (Fig. 13(a)) and the thrust coefficient (Fig. 13(b)). To maximize the performance of a ventral nozzle, the round edge should be considered part of the ventral system design.

\section{$\underline{\text { Swivel Nozzle with Yaw Control }}$}

Vanes were added internally to the swivel nozzle (Fig. 14) for yaw control. ${ }^{8}$ In this arrangement, the vanes were fixed but in practice the vane angle would vary. This innovative vectoring scheme could be applied to a STOVL aircraft to increase maneuverability and control. Internal vanes canted at $20^{\circ}$ were added to the swivel nozzle and tested at tailpipe-to-ambient pressure ratios from 1.6 to 5.0. In general, testing indicated that directing the ventral jet at subsonic velocities resulted in efficient vectoring of the ventral flow. The side force produced by the nozzle with vanes at a pressure ratio of 4.0 was up to 14 percent or more of the vertical force. At a tailpipe-to-ambient pressure ratio of 4.0 , the discharge coefficient decreased by at least 
6 percent and the thrust coefficient was unaffected by the internal vanes. An offset existed between the set internal vane angle of $20^{\circ}$ and the effective flow angle. The effective flow angle was calculated directly from the side and vertical force components. This angle, at a tailpipe-toambient pressure ratio of 4.0 , was $8^{\circ}$ for the swivel nozzle with four vanes and $10.5^{\circ}$ for the nozzle with seven vanes.

\section{Concluding Remarks}

The NASA Lewis research in offtakes and vertical lift systems to be used in advanced STOVL aircraft propulsion was presented. Progress has been made in the basic research areas, but there is much to be done and resources are limited. The future for STOVL-related research work at Lewis is largely dependent on the direction taken by Advanced Research Projects Agency (ARPA) and the U.S. Navy. They have contracts with industry to pursue technology validation experiments that may lead to the selection of a powered lift concept for an advanced STOVL strike fighter.

\section{$\underline{\text { References }}$}

1. McArdle, J.G., Esker, B.S., and Rhodes, J.A., "Internal Reversing Flow in a Tailpipe Offtake Configuration for SSTOVL Aircraft," NASA TM-105698, 1992.

2. McArdle, J.G., and Esker, B.S., "Effects of Flow-Path Variations on Internal Reversing Flow in a Tailpipe
Offtake Configuration for ASTOVL Aircraft," NASA TM-106149, 1993.

3. McArdle, J.G., and Smith, C.F., "Experimental and Analytical Study of Close-Coupled Ventral Nozzles For ASTOVL Aircraft," NASA TM-103170, 1990.

4. Esker, B.S., and Perusek, G.P., "Experimental Performance of Three Design Factors for Ventral Nozzles for SSTOVL Aircraft," NASA TM-105697, 1992.

5. Esker, B.S., and DeBonis, J.R., "Experimental and Analytical Studies of Flow Through a Ventral and Axial Exhaust Nozzle System for STOVL Aircraft," NASA TM-104364, 1991.

6. McArdle, J.G., and Esker, B.S., "Performance Characteristics of a Variable-Area Vane Nozzle for Vectoring an ASTOVL Exhaust Jet up to $45 \mathrm{deg}$," NASA TM-106114, 1993.

7. Esker, B.S., and McArdle, J.G., "Performance Characteristics of a One-Third-Scale, Vectorable Ventral Nozzle for SSTOVL Aircraft," NASA TM-103120, 1990.

8. Esker, B.S., and McArdle, J.G., "Experimental Performance of a Ventral Nozzle With Pitch and Yaw Vectoring Capability for SSTOVL Aircraft," NASA TM-106054, 1993. 


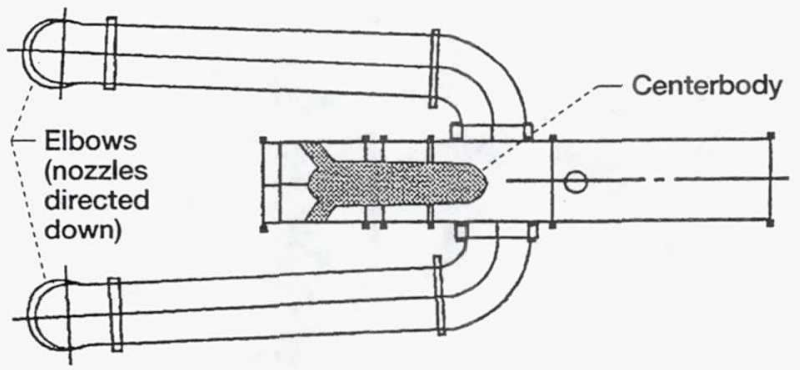

(a) Tailpipe with centerbody.

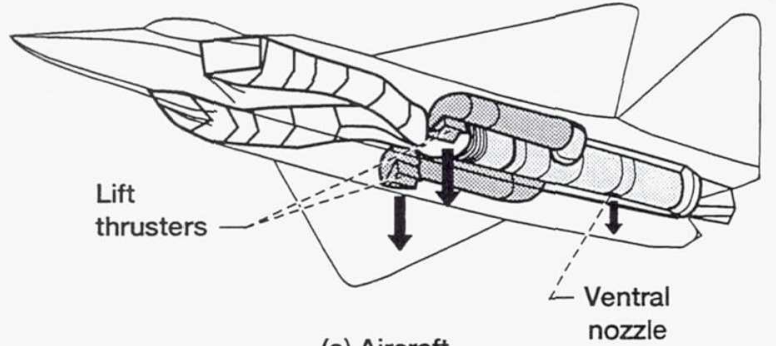

(a) Aircraft.
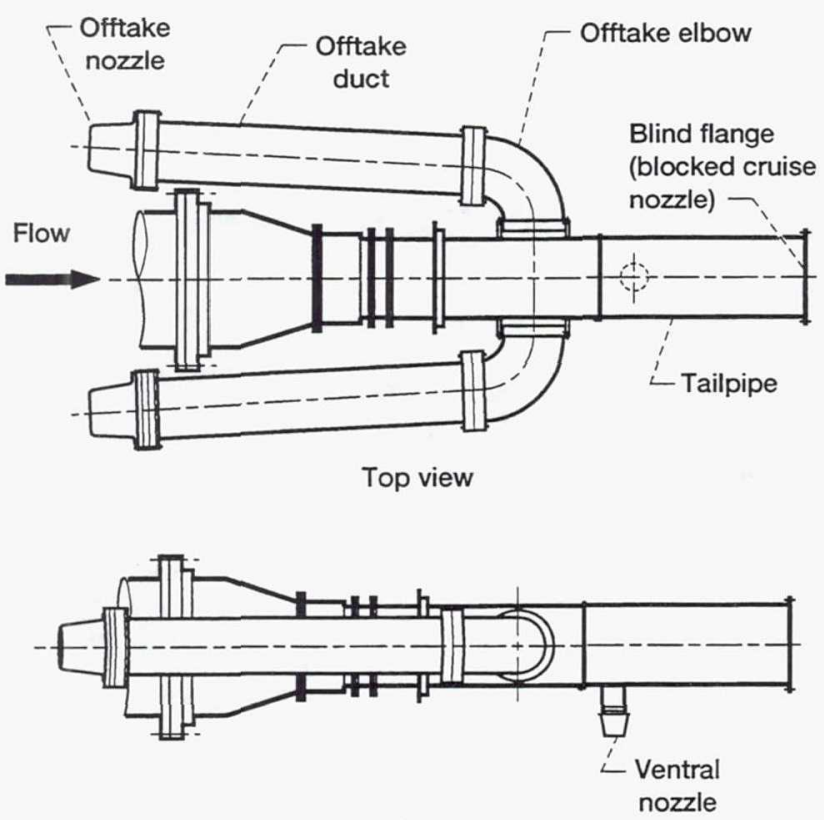

Side view

(b) Model tested.

Figure 1.-Tailpipe offtake experimental model.

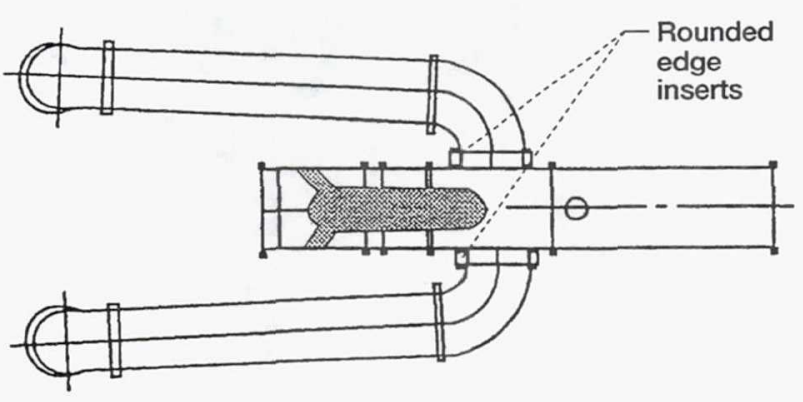

(b) Rounded edge at offtake.

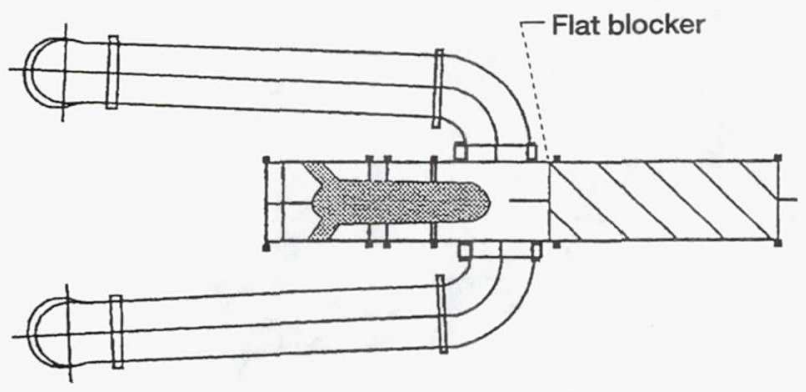

(c) Blocker (flat) near offtakes.

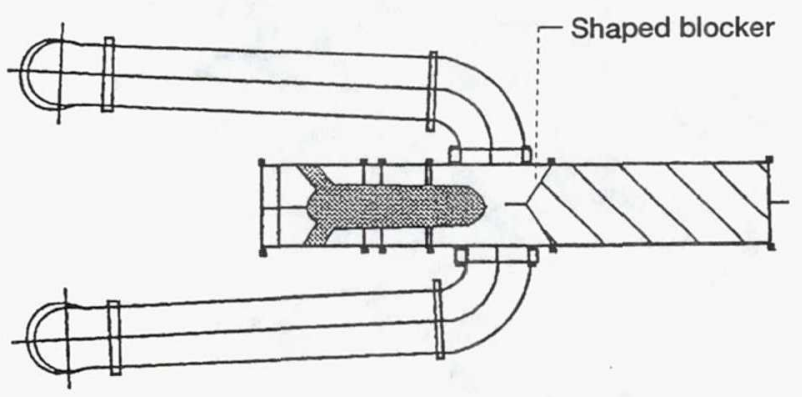

(d) Blocker (shaped) near offtakes.

Figure 2.-Configurations of offtake systems tested. 


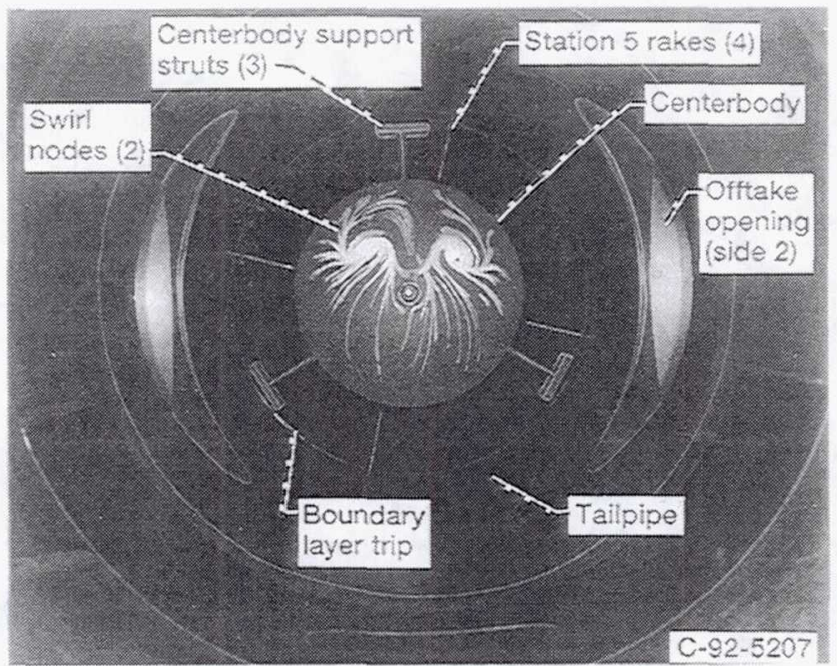

Figure 3.-Flow visualization paint streaks on centerbody of basic model (looking forward on tailpipe axis).

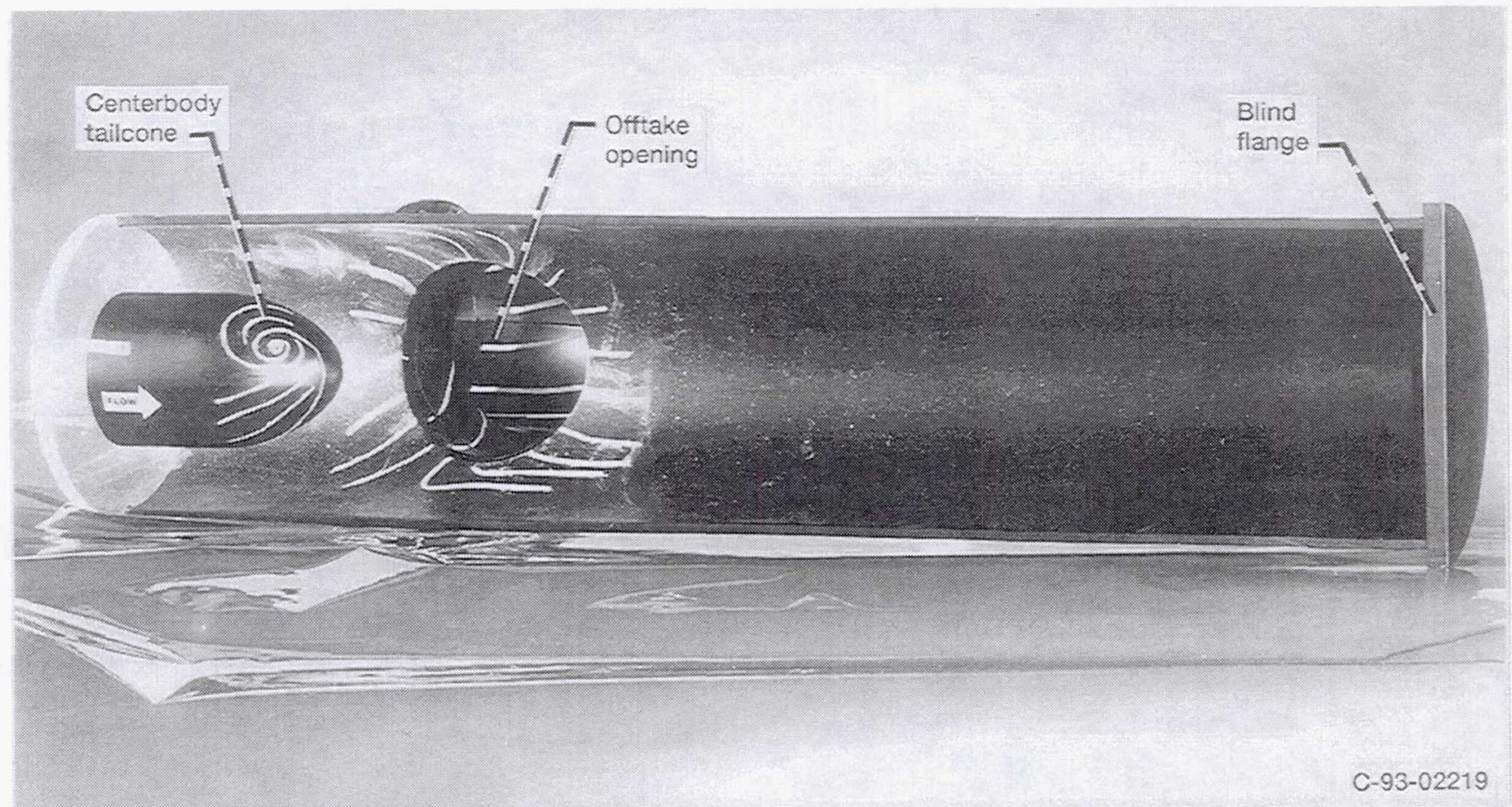

Figure 4.-Flow visualization streaks on scale mockup of basic model (tailpipe cut on plane of symmetry). 

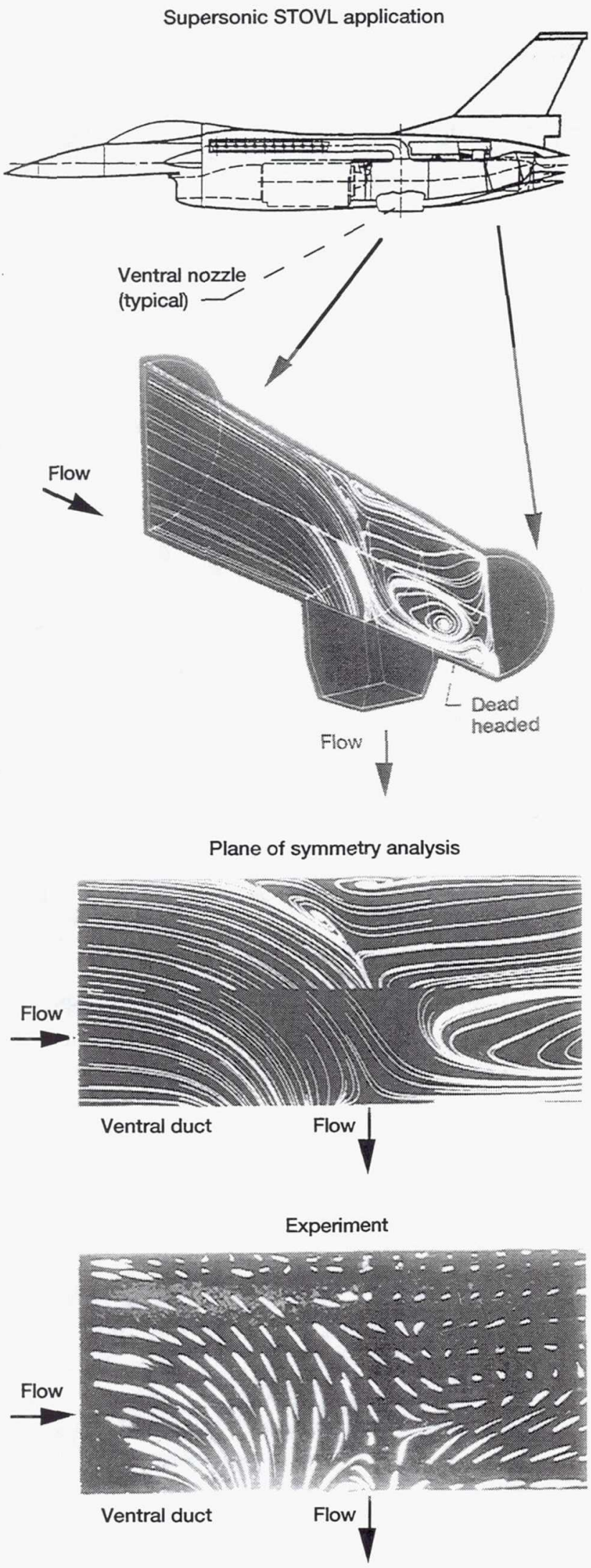

Figure 5.-Comparison of experimental and CFD analytical results.

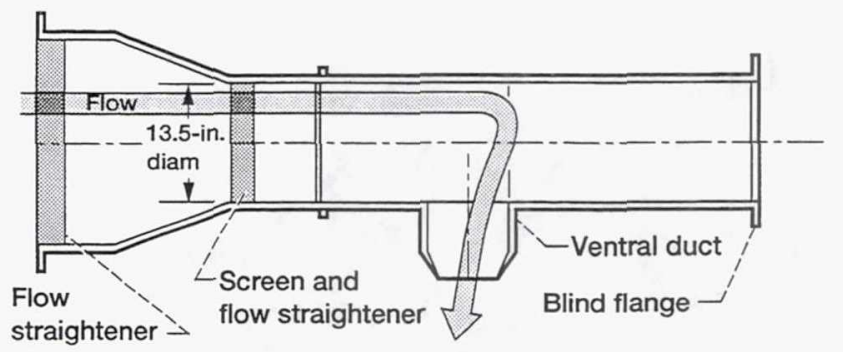

(a) Baseline ventral nozzle.

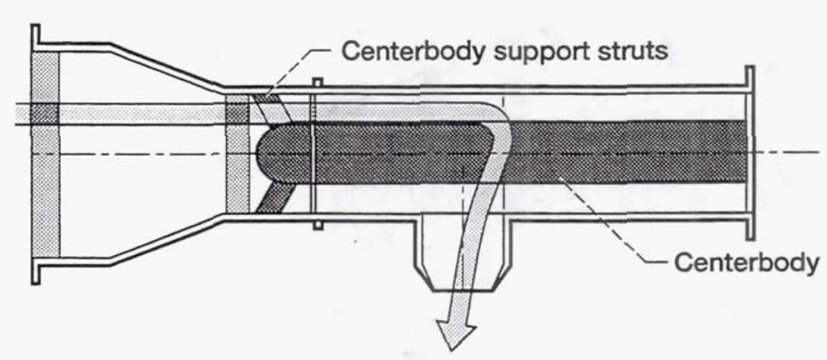

(b) Annular flow duct.

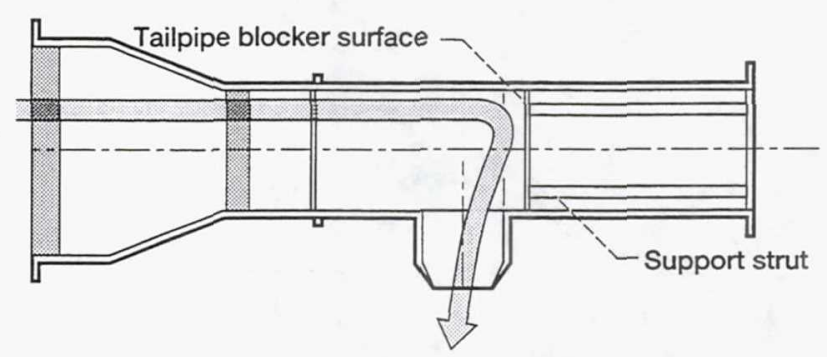

(c) Shortened tailpipe.

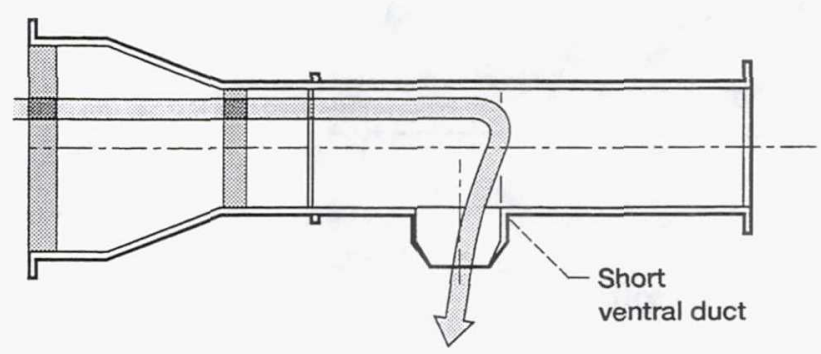

(d) Short ventral duct.

Figure 6.-Configurations of tailpipe and ventral nozzle variations. 


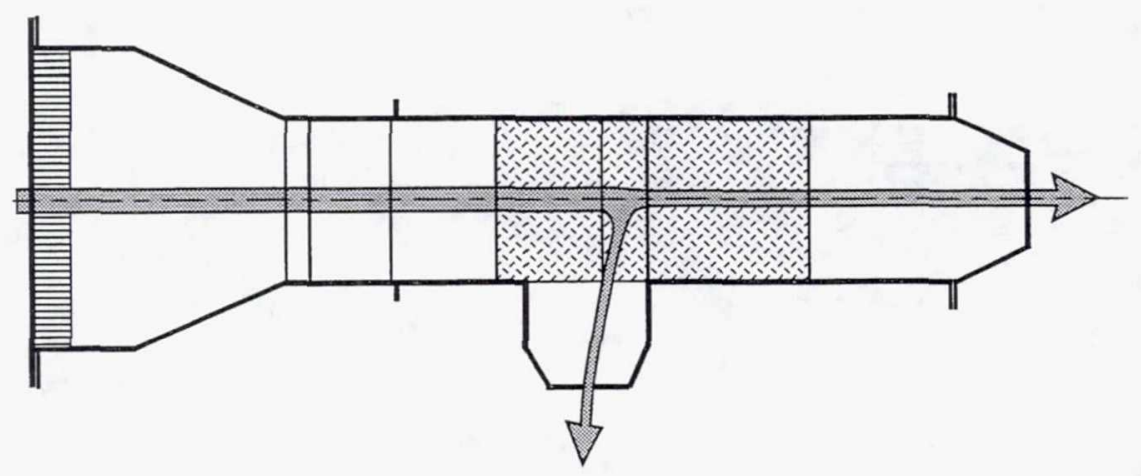

Figure 7.-Ventral and axial nozzle configuration.

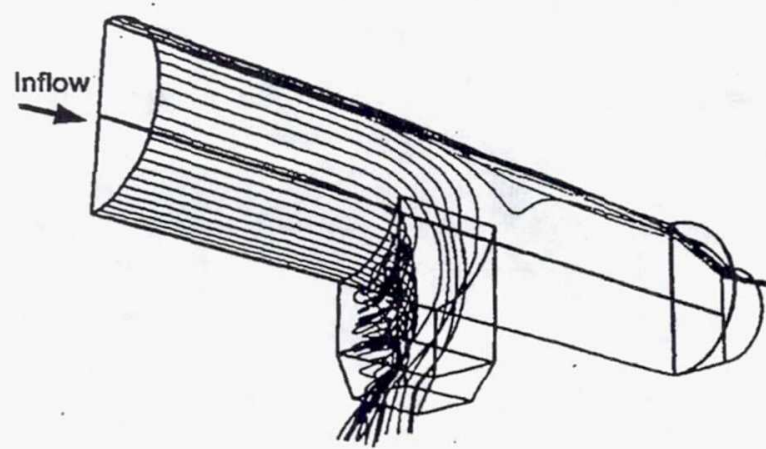

Figure 8.-Analytical particle traces in the boundary layer.

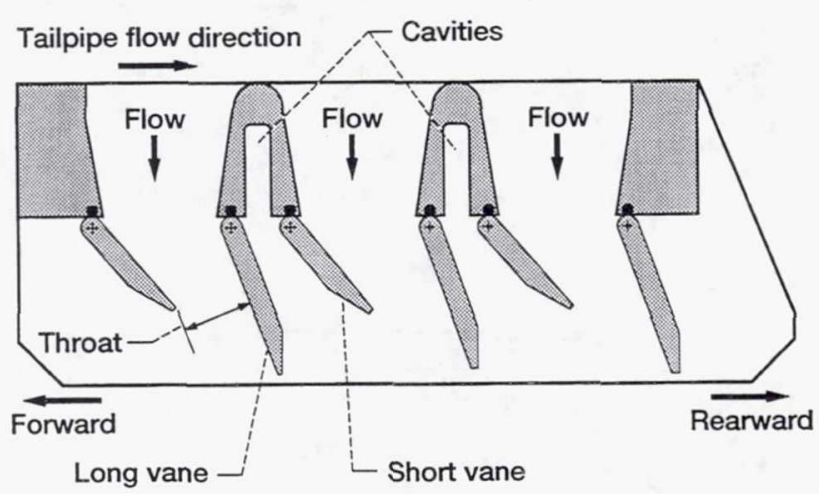

Figure 9.-Vane nozzle (cross section showing vane arrangement).
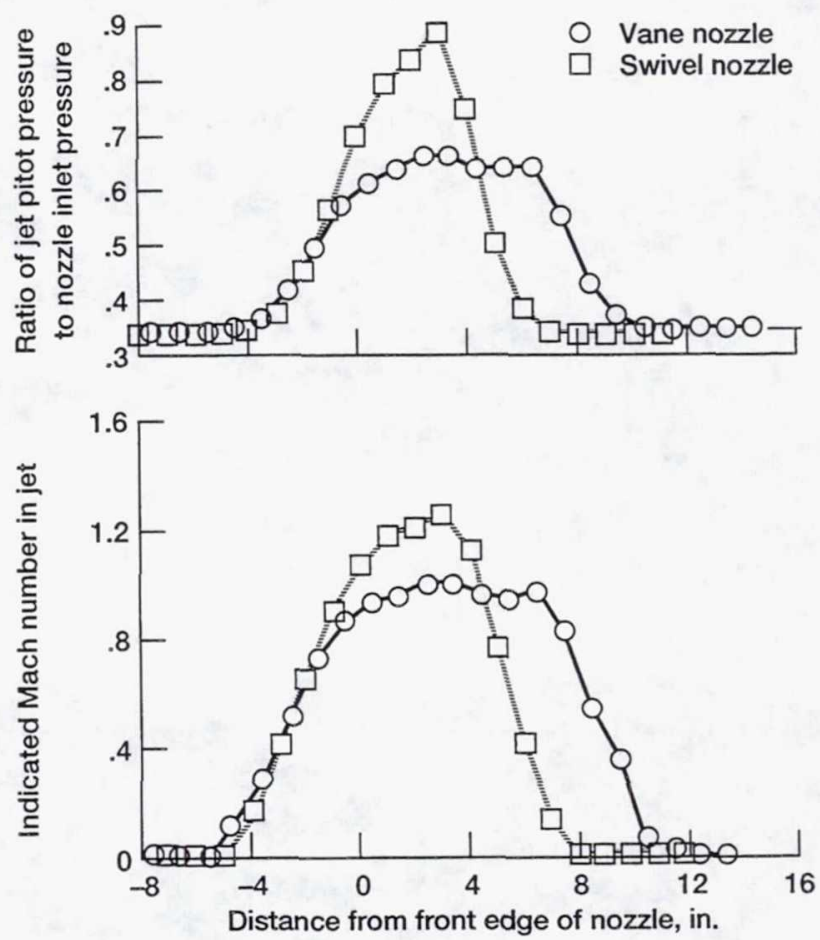

Figure 10.-Comparison of free jet wakes. Tailpipe pressure ratio, 3. 


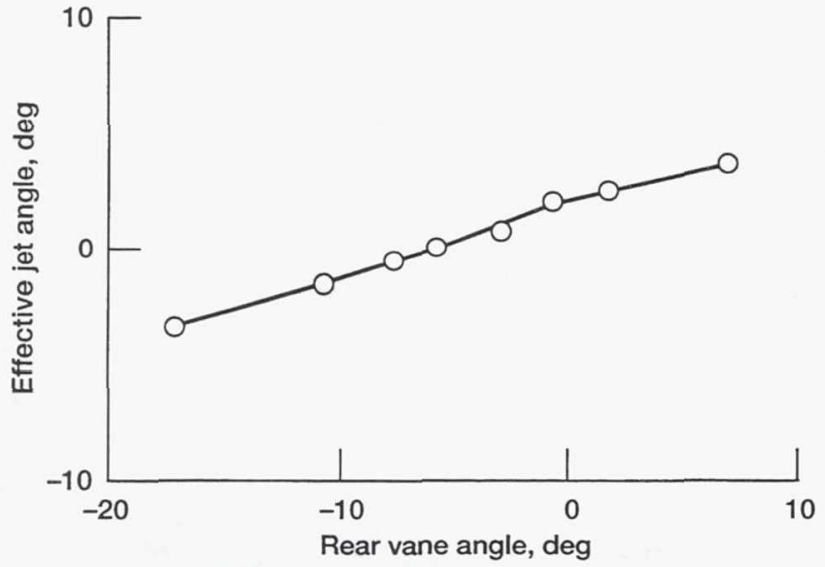

(a) Equal-length vanes.

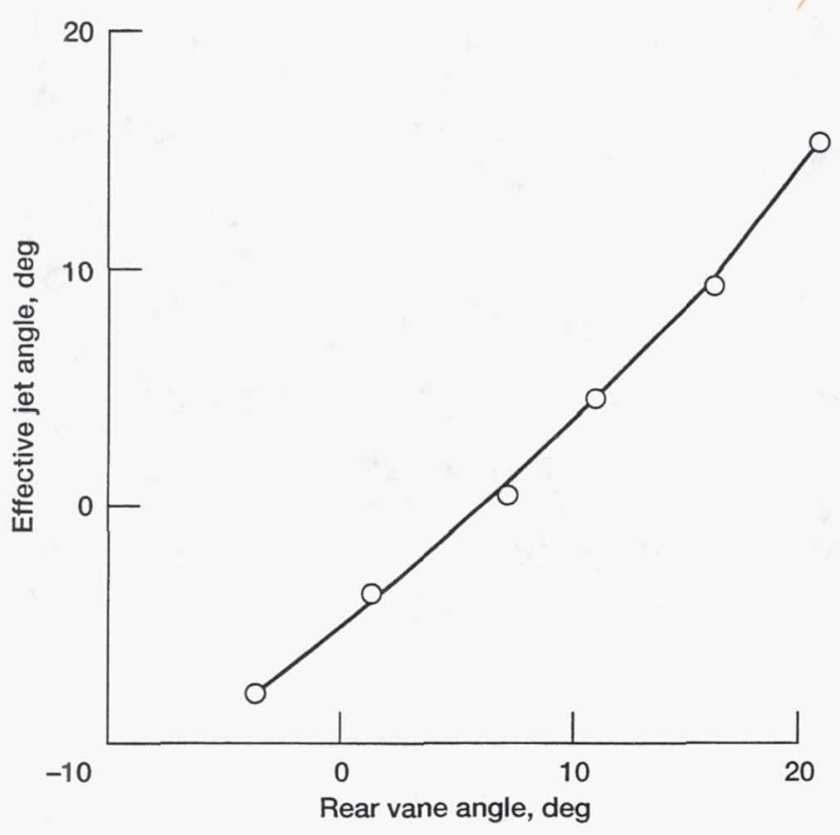

(b) Long-short vanes (long rear vane and short front vane).

Figure 11.-Vector characteristics of single-vaneset designs.

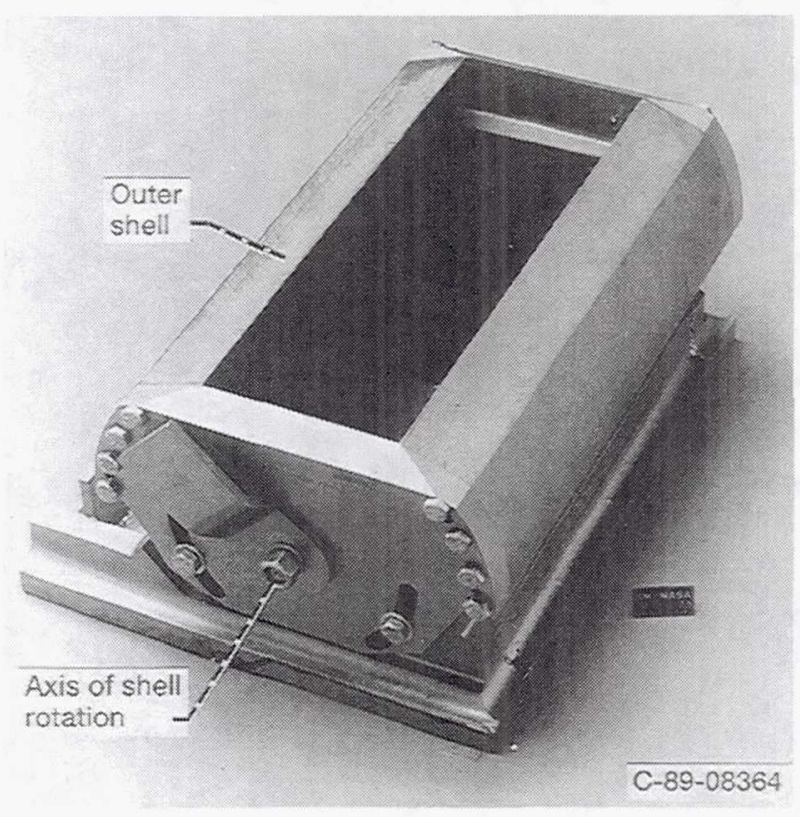

(a) In midposition.

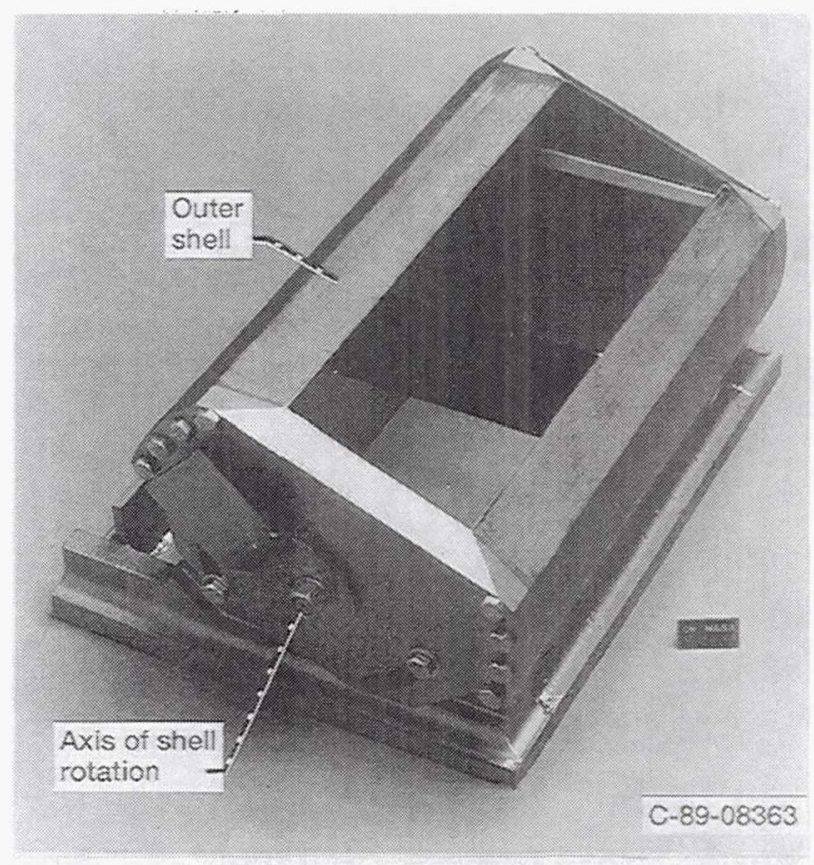

(b) In rotated position.

Figure 12.-Swivel nozzle. 


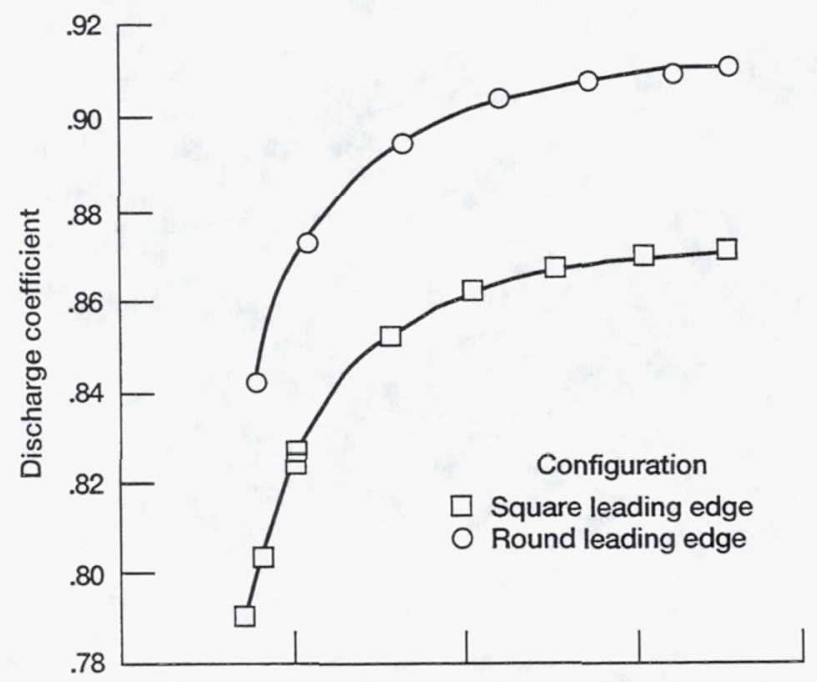

(a) Discharge coefficients. Vector angle setting, $0^{\circ}$.

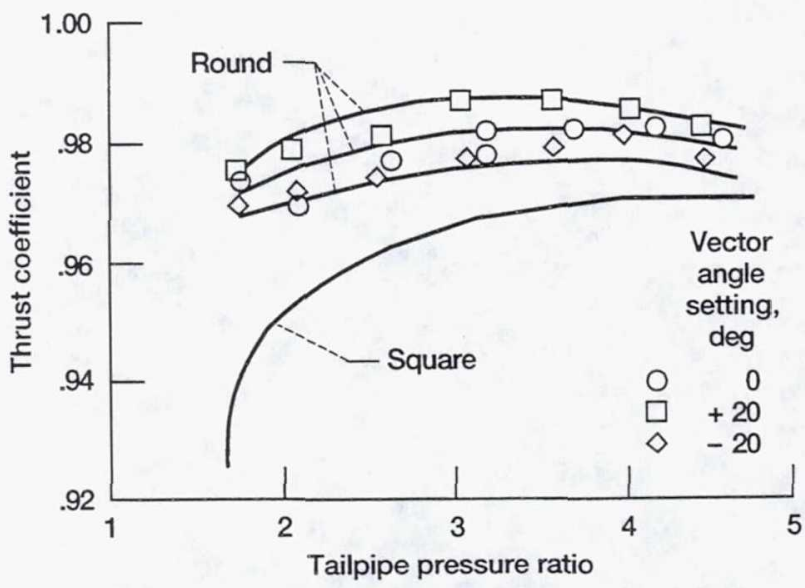

(b) Thrust coefficients.

Figure 13.-Comparison of discharge and thrust coefficients for both round and square leading-edge configurations.

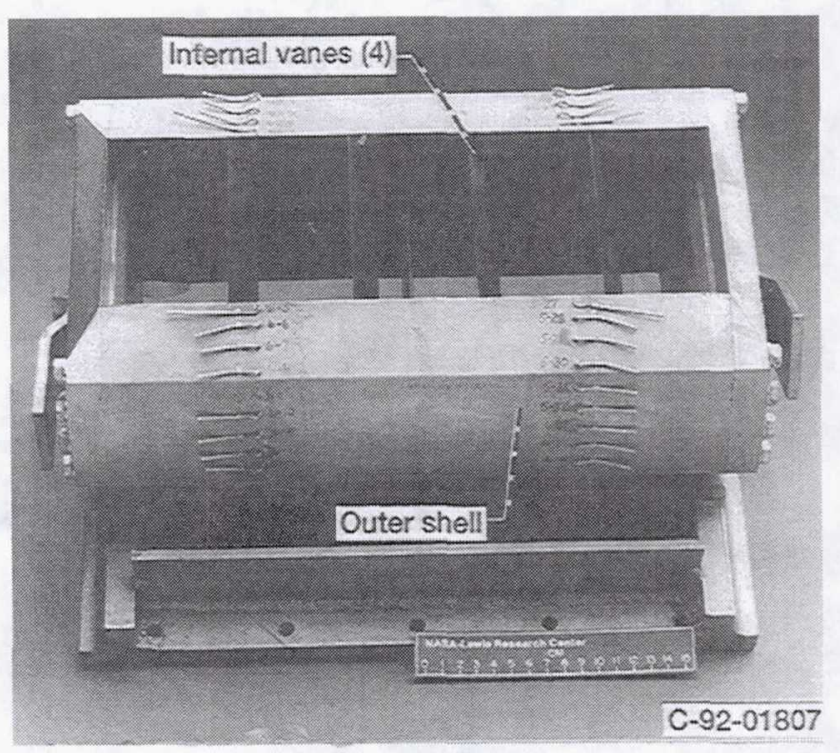

Figure 14. - Internal vanes for side force. Set of four vanes assembled into the swivel nozzle. Nozzle shown photographed at an oblique angle. 
Public reporting burden for this collection of information is estimated to average 1 hour per response, including the time for reviewing instructions, searching existing data sources, gathering and maintaining the data needed, and completing and reviewing the collection of information. Send comments regarding this burden estimate or any other aspect of this collection of information, including suggestions for reducing this burden, to Washington Headquarters Services, Directorate for Information Operations and Reports, 1215 Jefferson Davis Highway, Suite 1204, Arlington, VA 22202-4302, and to the Office of Management and Budget, Paperwork Reduction Project (0704-0188), Washington, DC 20503.

\begin{tabular}{|l|l|l|}
\hline 1. AGENCY USE ONLY (Leave blank) & $\begin{array}{r}\text { 2. REPORT DATE } \\
\text { December } 1993\end{array}$ & $\begin{array}{r}\text { 3. REPORT TYPE AND DATES COVERED } \\
\text { Technical Memorandum }\end{array}$
\end{tabular}

\section{TITLE AND SUBTITLE}

Overview of STOVL Aircraft Propulsion Research

Offtakes and Vertical Lift Systems

6. AUTHOR(S)

\section{FUNDING NUMBERS}

WU-505-68-32

Thomas J. Biesiadny, Jack G. McArdle, and Barbara S. Esker

7. PERFORMING ORGANIZATION NAME(S) AND ADDRESS(ES)

National Aeronautics and Space Administration

Lewis Research Center

Cleveland, Ohio 44135-3191

9. SPONSORING/MONITORING AGENCY NAME(S) AND ADDRESS(ES)

National Aeronautics and Space Administration

Washington, D.C. 20546-0001
8. PERFORMING ORGANIZATION REPORT NUMBER

E-8207

10. SPONSORING/MONITORING AGENCY REPORT NUMBER

NASA TM-106387

AIAA-93-4865

11. SUPPLEMENTARY NOTES

Prepared for the International Powered Lift Conference sponsored by the American Institute of Aeronautics and Astronautics, Santa Clara, California, December 1-3, 1993. Responsible person, Thomas J. Biesiadny, (216) 433-3967.

12a. DISTRIBUTION/AVAILABILITY STATEMENT 12b. DISTRIBUTION CODE

Unclassified - Unlimited

Subject Category 07

13. ABSTRACT (Maximum 200 words)

The overall Short Takeoff and Vertical Landing (STOVL) Aircraft Propulsion Research Program includes key technologies involving offtake systems, vertical lift systems, hot gas ingestion, STOVL augmentors and integrated flight propulsion controls. A part of the NASA Lewis work involving STOVL aircraft propulsion systems is presented with the emphasis on component-level experiments and analysis related to offtakes and vertical lift systems.

\begin{tabular}{|c|c|}
\hline 14. SUBJECT TERMS \\
Propulsion; STOVL; Aeronautical propulsion research \\
\hline $\begin{array}{c}\text { 17. SECURITY CLASSIFICATION } \\
\text { OF REPORT } \\
\text { Unclassified }\end{array}$ & $\begin{array}{c}\text { 18. SECURITY CLASSIFICATION } \\
\text { OF THIS PAGE } \\
\text { Unclassified }\end{array}$ \\
\hline
\end{tabular}

\begin{tabular}{|c|c|}
\hline & $\begin{array}{l}\text { 15. NUMBER OF PAGES } \\
14\end{array}$ \\
\hline & $\begin{array}{c}\text { 16. PRICE CODE } \\
\mathrm{AO} 3\end{array}$ \\
\hline $\begin{array}{l}\text { 19. SECURITY CLASSIFICATION } \\
\text { OF ABSTRACT } \\
\text { Unclassified }\end{array}$ & 20. LIMITATION OF ABSTRACT \\
\hline
\end{tabular}

